\title{
Strategic Management Accounting Analysis of G8 Education Limited
}

\author{
Sizhen Liu \\ University of New South Whale, Sydney NSW 2052, Australia \\ ABSTRACT. G8 Education offers child care and education service in Australia and \\ Singapore through a range of high-quality brands. This report proposes some \\ advices to G8 Education, which includes analysis of G8 Education's threats, \\ opportunities, weaknesses and strengths, key capabilities, followed by major \\ stakeholder analysis. The generic business strategy of G8 Education will be \\ explained, with the corporate balanced scorecard and the key strategies.
}

KEYWORDS: strategic management, accounting analysis, G8 Education

\section{Introduction}

G8 Education offers child care and education service in Australia and Singapore through a range of high-quality brands. This report proposes some advices to G8 Education, which includes analysis of G8 Education's threats, opportunities, weaknesses and strengths, key capabilities, followed by major stakeholder analysis. The generic business strategy of G8 Education will be explained, with the corporate balanced scorecard and the key strategies.

\section{Tow Analysis}

\subsection{Threats}

\subsubsection{Increased Competition}

G8 Education faces competitive pressure from growing early childhood education industry. In Australia, there are around 17000 government approved child care centres with $4.6 \%$ annual growth rate. The Australian Childcare Alliance said, there will be 90,000 childcare places if another 1100 centres completed (Malone 2018). Intense competition from existing and new industry rivals may decrease G8 Education revenue and profits. 


\subsubsection{Regulatory Environment}

The license is necessary to operate a child centre in Australia. BecLloyd mentioned that "strict regulation surrounding child care centre planning and the long application processes may cause industry supply to further lag.” (Lloyd 2018) The difficulty of obtaining a license will obstruct G8 Education expanding plan.

\subsubsection{Wage Pressure}

G8 Education has to face the problem of wage pressure because of its intensive labor. According to the G8 Education Annual Report, there is a total of 9927 employees and employees’ expense is 45 million (G8 2017, p.48). Moreover, the increase in staff requirements per centre and hourly rate increases will lead to high cost of labor, then the revenue will be decreased.

\subsection{Smaller educator to child ratio}

"Ongoing workforce shortages are inhibiting Australia's ability to meet increasing demands for high-quality child care and aged care.” Marilyn Harrington mentioned. (Harrington and Jolly 2018) High-quality educator in Australia child care industry is insufficient. If G8 Education is expanding, it will face the problem of smaller educator to child ratio.

\subsubsection{The threat of non-profit child care centre}

Non-profit child care centres will share the market with theirs. The office of early childhood education mentioned that the market share of not-for-profit childcare centre will increase from 22 to 34 percent. The childcare market expects to be more stable in a greater diversity situation (State of Child care in Australia 2010, p.6). Non-profit child centre gives more choice for parents and reduce the market shared pf private child care centre such as G8 Education.

\subsection{Weakness}

\subsubsection{Labor intensive}

G8 Education owns 516 centres and 9927 employees (G8 2017, p.7). In the future, the government requires childcare centre hold more educators. Labor is the largest cost which being $60 \%-65 \%$ of total cost, so that the revenue will not be significant. Labor intensive may even result in some centres shut down.

\subsubsection{Limited market}

G8 Education operations are limited to Australia and Singapore, with majority of their revenue being generated in Australia. Limited market not only limits revenue but also increases operation risk. This limitation restricts G8 Education from being able to reduce its operational risk, unlike its competitors. 


\subsubsection{Unstable Management}

A number of changes had happened in the Group’s Board during 2017 (G8 2017, p.13). After Gary Carroll, Chris Scott and Matthew Reynolds, the Group's Board was stabilized in 2017. Unstable management may result in share price going down and confusing management.

\subsubsection{Excessive centres}

G8 Education owns excessive centres in Australia. It cannot promise every centre with high quality. According to Indeed survey, there are some negative valuations such as disorganized centres and the children were ignored or treated horribly. Expanding without high quality may ruin G8 Education's reputation.

\subsubsection{Fragile and obsolete hardware}

The equipment is fragile in some G8 Education centres. If there are some natural disasters such as earthquake, the equipment will be destroyed and hurt children. The advanced equipment is necessary for a high quality education centre. Fragile and obsolete hardware will result in the loss of competitiveness.

\subsection{Opportunities}

\subsubsection{High female employment rate and disposable income}

Both high levels of female participation in the workforce and high disposable personal income boost child care industry. More female join in the workforce provides more labors for the child care industry. Moreover, The Australia Disposable Personal Income expects to be around 323574.20 AUD million in 2020. (Tradingeconomics 2018). Expensive tuition is afforded by parents with high disposable income.

\subsubsection{High demand for Child care centres}

Bankwest discloses that 100000 childcare centre will be needed because children aged 12 and under will grow by 7.8\% in the five years (Bankwest 2018). Almost 3.5 million children drive demand for childcare in Australia. G8 Education can expand its centres to satisfy this high demand.

\subsubsection{Government Subsidy}

Increased childcare subsidy make childcare industry prosper. According to Bankwest, "the government's childcare fee assistance is expected to rise by $38.8 \%$ in the four years to June 2021 to $\$ 10.0$ billion, up from $\$ 7.2$ billion in June 2017” (Bankwest 2018). What the government will do is to make child care affordable for family with low income and reduce the cost of operation in childcare centre.

\subsubsection{Early childhood education and care culture}

In Australia, people accept childcare culture and would like to pay for early childhood education. By the end of the 1890s, the development of kindergarten

\section{Published by Francis Academic Press, UK}


movements was introduced into Australia and some fee-charging kindergartens were appeared (Press and Hayes 2000).

\subsubsection{Development of technology}

As the technology developed, it provides a new way to support early childhood education. Chip Donohue mentioned that using of computers and other digital technologies will be popular in early childhood education, and technology is a new and interesting tool to improve the quality of early childhood education (Donohue 2018).

\subsection{Strengths}

\subsubsection{Good Balance sheet}

“The Group significantly strengthened its Balance Sheet during 2017 as well as raising approximately \$200 million in additional equity” (G8 2017, p.13). Balance sheet remains geared, which will enable G8 Education to continue to acquire.

\subsubsection{Multi-branded strategy}

G8 Education owns 23 brands of childcare services. It may not only reduce brand risk but also leave less shelf space for competitors and obtain more for itself.

\subsubsection{Attractive Remuneration}

Attractive remuneration motivates its employees. In the G8 education, remuneration includes total fixed remuneration, short-term incentives and long-term incentives (G8 2017, p.33). G8 Education affords competitive salary to attract high-quality educators.

\subsubsection{New Technology Innovation:}

SD-WAN in introduction by G8 Education which provides digital learning initiatives and tools to help parents see progress and interact with their children during their first years of formal education (FQ Editor 2018). The new platform builds an interesting cycle between children, parents and educators. It maintains royal relationship with customers.

\subsubsection{Location}

Location is a key factor for parents to choose childcare centres. Parent choose childcare centre at a safe area. G8 education centres usually located in safe areas such as near the police station and wealthy people area. The safe and convenient location is one of reasons that parents would choose G8 education.

\section{Key capability analysis for G8 Education}

The first key capability is that G8 Education has an ability to maintain high levels of service provision to Australia's communities.

\section{Published by Francis Academic Press, UK}




\subsection{Resources Utilized}

\subsubsection{Tangible - Financial}

The significant improvement in 2017 balance sheet has directly provided powerful support to maintain high-quality education services in Australia. G8 Education generated a 2.2\% increase in underlying EBIT and operating cash flows of \$92 million (G8 2017, p.16).

The new government childcare subsidy would replace the existing benefit and be made from 1 July 2018. The rising funding by 38.8\% from $\$ 7.2$ billion to $\$ 10$ billion would strengthen G8 market domination in the next four years (Australian Government Department of Human Service 2018).

\subsubsection{Intangible - Technology}

Macquarie's SD-WAN platform was a major breakthrough in children education innovation, due to enhancing the timely communication between educators and parents. The improved network includes sharing children participation activities during learning in the media and providing regular feedback on children's progress to their parents, which could maintain the high-level education services in Australia (FQ Editor 2018).

\subsubsection{Human - Skill and know-how}

G8 continues to significantly invest in professional and leadership development programs in order to improve service quality and skills of team members. The outstanding executive leaders would receive the senior leadership development program and build leadership capability in the Group (G8 2017, p.16).

\subsection{Core competency assessment}

\subsubsection{Valuable - Yes}

The customers both parents and children increasingly value the child education quality service. The better early education would help children build up the cognitive system in advance.

\subsubsection{Rare - Yes}

G8 has a particular technology innovation SD-WAN platform, which could maintain the special education service compared to other preschool education in Australia.

\subsubsection{Costly to imitate - Yes}

In order to keep high-quality education service in the competitive market, the extremely large investments in teaching technology and training of high-caliber personnel should not be ignored. There is some casual ambiguity in understanding how the training mode of high-level educators has been achieved.

\section{Published by Francis Academic Press, UK}




\subsubsection{Able to be exploited by an organization's progress - Yes}

With continuous teaching development programs and leadership capability building, high performance of education service will further enhance the brand reputation for excellent quality children education. Therefore, It is a sustained competitive advantage since it meets four attributes of VRIO framework. The second key capability is that G8 Education has an ability to keep the original customers and attract more new customers.

\subsection{Resources Utilized}

\subsubsection{Tangible - Physical}

There is a total number of centres 495 in Australia and 21 in Singapore, including acquired 37 early education centres and disposed of 22 centres in Australia up to 31 December 2017 (G8 2017, p.14). Using the big scale to provide differentiated market leading services-focusing on the quality of education and care, breadth of offer and a highly engaging experience for families are a dominant physical resource to expand consumer groups (G8 2017, p.16).

\subsubsection{Intangible - Reputation}

The good reputation of high- Intangible - Reputation quality children education has been well accepted by the public. There are 32\% of centres being assessed as exceeding National Quality Standards in 2017 (G8 2017, p.15).

\subsubsection{Intangible -Culture}

The key culture of Passion, Integrity, Compassion, Innovation and Dedication across the G8 Group has improved the customer identity and satisfaction, which could build long-term relationships with current customers and attract new consumers (G8, 2017, p.16).

\subsubsection{Human - Motivation}

The remuneration mix system for employees is divided into three types, including fixed remuneration, short-term incentives and long-term incentives. Theses remuneration packages are directly to encourage management to improve the performance by rewarding and achieving the value targets through expanding customers (G8 2017, p.33).

\subsection{Core competency assessment}

\subsubsection{Valuable - Yes}

The strong customer group would not only make visible profit for business directly, but also a good way to establish a good reputation in the competitive education market.

\section{Published by Francis Academic Press, UK}




\subsubsection{Rare - Yes}

G8 Education has become the largest for-profit childcare and early education provider in Australia. It is rare that the outstanding centres business network over Australia and Singapore (Australia and New Zealand Business Report 2017).

\subsubsection{Costly to imitate - Yes}

Due to the social complexity of varying education quality, G8 with high-level service combining traditional education and technology innovation teaching is costly to imitate by rivals.

\subsubsection{Able to be exploited by an organization's progress - Yes}

The differentiate service of G8 Education could sustainably attract new consumers and build customer loyalty for the group. Therefore, It is a sustained competitive advantage because it meets all core competencies.

\section{Generic Business Level Strategy}

G8 Education adopted the differentiation strategy to attract customers. There are three attributes of the differentiation strategy. Firstly, Multiple brands and services. G8 Education embraces a wide range of modes to support services, including nearly 300 workshops and online learning modules via the 'learning lounge'. The attribute of multiple brands is another significant one to make the organization differentiated (G8 2017, pp.19). Secondly, Zero-harm workplace. G8 Education aims to achieve a zero-harm workplace. Safe leadership and related training are included to support centre managers such as First Aid and Safety. Furthermore, fitness and well-being programs help people improve their health and safety (G8 2017, pp.19) Thirdly, Advanced technology. The organization provides advanced technology including upgraded intranet, file sharing technology and upgraded communication equipment, which improve the satisfaction of customers, for instance, SD - WAN platform and virtual meetings (G8 2017, pp.18) Therefore, G8 Education Limited has been pursuing a differentiation strategy, which contributes to being the leading provider of this field in Australia.

\section{Strategy Review and Shareholder Value Implication}

The Strategy one is to focus on education quality, value, and customer experience.

Suitability: The culture of early childhood education and care has been deeply ingrained for a long time. G8 Education captured this trend. By implementing the quality and customer experience focusing strategy, it reinforces its advantage over competitors, attracting more customers. Therefore, G8 Education can further expand its market share and get more profit. However, Regulatory environment may restrict this industry's branch expansion. The legal restriction raises a barrier in G8's way of opening more education centres. To overcome this barrier, G8 Education adjusts its 
strategy to drive occupancy in existing centres. With more customers tied to current centres, G8 Education would achieve its goal of revenue increasing.

Feasibility: G8 Education applied advanced technologies in its education process. G8 Education invested funds in improving technologies and facilities. With supporting of the technical resources, G8 Education can raise its education quality and customer experience management to a higher level. On the other hand, G8 Education Group's main market is limited to Australia. Although G8 Education acquired subsidiaries overseas, its main market locates in Australia. This concentration exposes the company to a dependency risk and limit its economic growth. By driving occupancy in centres, G8 Education maintains its revenue.

Acceptability: Customers would choose an education centre with high quality. Besides, customer relationship management of the strategy contributes to attracting more customers. Improving education quality requires the support of more teaching equipment, textbooks and even toys. This means suppliers will get more orders from this strategy. As f or employees, the quality and education focusing strategy is more likely to bring employees salary increasing and more training programs.

Consistency: This strategy is consistent with G8 Education's differentiation strategy. G8 Education highlights education quality and customer experience, making it more various to the competitors. Customers choosing G8 Education are more willing to pay the price premium for it. Shareholder value implication: With the driving occupancy strategy, G8 Education will acquire more customers and expand its market share. Although salary and purchasing cost may also increase, it brings more profit margin. As a result, it provides benefit to the company in the long run and shareholder value is maximized.

Another strategy is about enhancing professional and leadership training and reengineering incentive framework.

Suitability: There are high female employment rate and high disposable income in Australia. The macroeconomic circumstances boost child care industry. Through enhanced training program and reconstructed incentive framework, G8 Education acquires the most capable employees with a more balanced staffing structure. However, there is a tendency of smaller educator to child ratio due to workforce shortage, affecting the child care quality and customer experience. To cope with this tendency, G8 Education adopts the strategy of enhancing training program and incentive framework. Therefore, more qualified educators are attracted as well as trained, allowing G8 to remain a more reasonable educator to child ratio.

Feasibility: G8 Education's balance sheet reveals it has abundant funds to support its ongoing operation. G8 Education's free cash flow allows it to perform high quality employee training program and set up competitive enough incentive framework. In return, G8 Education raises its education quality and customer satisfactory. On the other hand, with wages being $60-65 \%$ of costs, labour expense becomes a constraint on G8's ongoing operation. The high salary expenses lead to a lower margin to G8 Education. By enhancing training program and a more balanced incentive framework, G8 Education figures out an alternative method to raise 
employee benefit rather than simply raise their wages. In this way, G8 Education overcomes the wage cost pressure.

Acceptability: G8's service quality will be improved as employees get more motivation. As a result, customers are more satisfied. As for suppliers, the professional and leadership training program will require extra resource and other kinds of support. This generates more contracts to suppliers. Moreover, this strategy directly raises the level of employees' welfare, complying with the interest of employees.

Consistency: Being employer of choice is consistent with G8 Education's differentiation strategy. Competent educators are the most important resource in this industry. G8 Education group thus provides better education service through this strategy. Shareholder value implication: This strategy complies with shareholders' interest. Enhancing staff training and reconstructing incentive framework help improve education quality and customer satisfactory, resulting in more revenue. In addition, it increases employees' efficiency through reward motivation. Both two factors will bring more profit to the company and therefore shareholders' return is increased. 


\section{Corporate Balanced Scorecard Strategy Map}

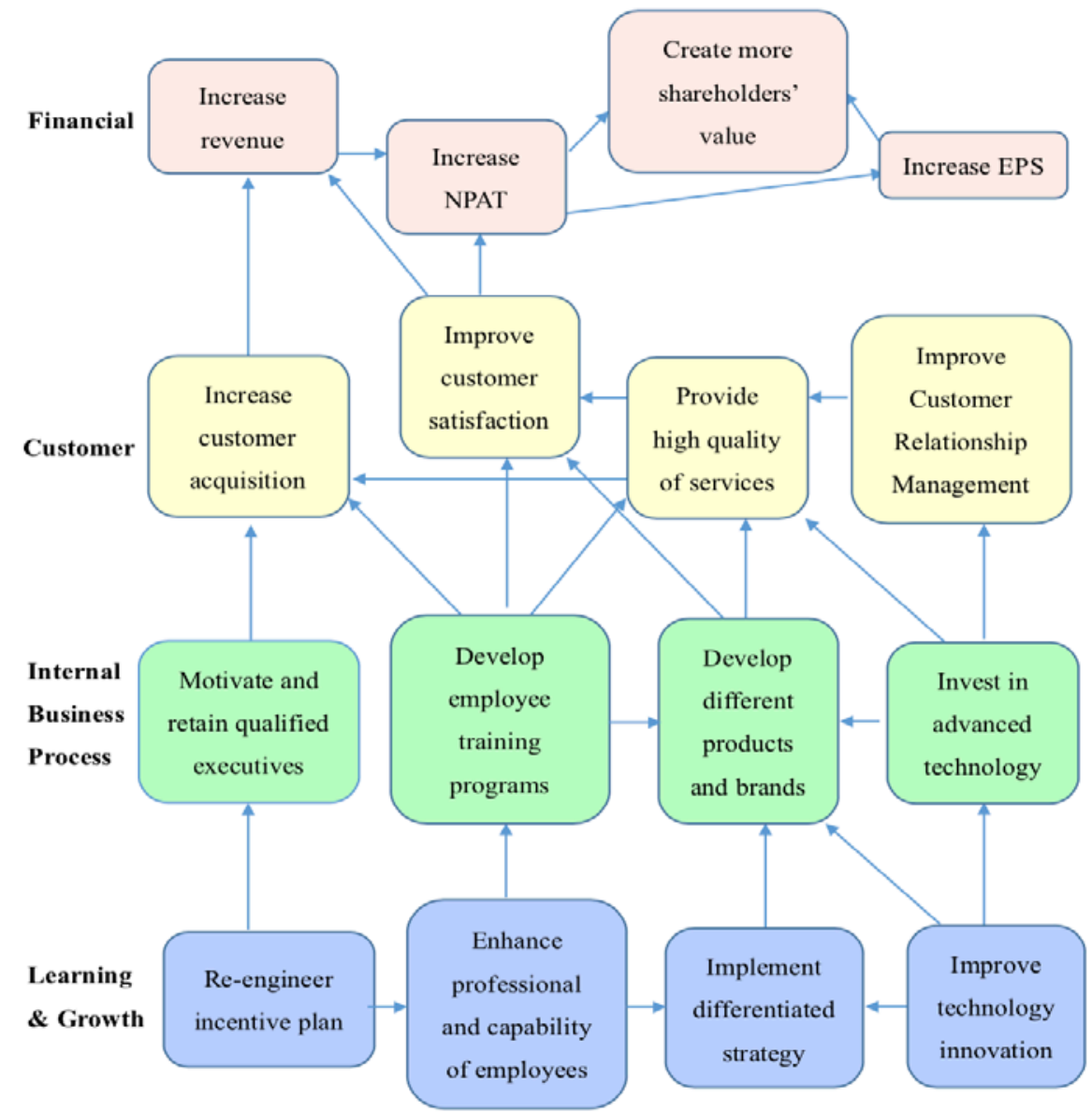

\section{Conclusion}

In recent years, the child care industry is developing rapidly due to the high demand for early childhood education. Therefore, the increased competitors and non-profit child care centres cause significant pressure on the development of G8 Education. However, G8 Education has been recognized as a leading private childcare operator in Australia with a strong reputation and high level of service.

TOWS analysis presents G8 Education in both bad and good external environments such as government subsidiary and intensive competition. Through the driving existing centres occupancy strategy and employee acquiring strategy, G8 Education manages to overcome its current constraints and maintains the competitive advantages. Furthermore, the core competencies mentioned are the

\section{Published by Francis Academic Press, UK}


ability to maintain high-quality provision to Australia's communities, as well as keep the original customers and attract more new customers. After the VRIO framework analysis, these two capabilities are both sustained competitive advantages. Moreover, major stakeholder analysis shows that though actions may increase the expense and reduce the value, most of them are aligned with the shareholders' value to improve productivity and increase the revenue to cover the expense. On the generic strategic level, G8 Education applies the differentiation strategy. The last but not the least important is that from the balanced scorecard perspective, G8 aims to improve customers' satisfaction by implementing different strategies and internal business processes. The ultimate goal of G8 Education is to create more value for shareholders by increasing the net profit.

However, G8 Education has shown a revenue decline trend in recent years, which should raise the vigilance of corporate management in order to achieve better performance in the future.

\section{References}

[1]Australia Governmlent Department of Human Service 2018, 'Child Care $\begin{array}{llll}\text { Subsidy', } & \text { accessed } & 14 & \text { Sept. }\end{array}$ $<$ https://www.humanservices.gov.au/individuals/services/centrelink/child-caresubsidy>

[2] Bankwest 2018, 'Bankwest Future business: Focus on Childcare’, accessed 15 Sept.

$<$ https://www.bankwest.com.au/content/dam/bankwest/documents/business/insig hts/focus-on-childcare-2018.pdf>

[3] Donohue, C. 2018, 'Technology in Early Childhood Education', accessed 15 Sept. 2018, <https://www.childcareexchange.com/library/5015417.pdf>

[4] Editor, F 2018, 'Macquarie Telecom to provide SD-WAN services to 500 G8 Education centres across Australia', accessed 14 Sept. 2018, <https://www.fifthquadrant.com.au/cx-spotlight- news/macquarie-telecom-toprovide-sd-wan-services-to-500-g8-education-centres-across-australia>

[5] G8 Education 2014, 'G8 Education Annual Report', accessed14 Sept. 2018, <https://g8education.edu.au/wpcontent/uploads/2013/09/Annual-Report-2014.pdf >

[6] G8 Education 2015, 'G8 Education Annual Report', accessed 14Sept. 2018, $<$ https://g8education.edu.au/wp-content/uploads/2013/09/2015-Annual-Reportfinal-as-at 210216_CPS-Version-345pm.pdf> 